\title{
CAPILARIDAD DE LA MANUFACTURA TEXTIL EN LA PLANA DE CASTELLÓ. EL CASO DE ONDA EN EL SIGLO XV
}

\author{
CAPILLARITY OF THE TEXTILE MANUFACTURE IN \\ «LA PLANA DE CASTELLÓ». ONDA 15th CENTURY
}

Resumen: Onda, localidad con un volumen demográfico oscilante entre 300-600 fuegos en el transcurso del siglo $\mathrm{XV}$, con presencia de mudéjares y judíos en el tejido productivo local, es una nueva pieza del puzzle que permite ver la capilaridad de la manufactura textil lanera a nivel comarcal (Plana de Castelló), tanto en la producción de paños, como en el comercio de materias primas o tránsito de artesanos. Para aproximarnos a esta situación hemos utilizado fundamentalmente las series del justicia de la villa conservadas en el Archivo del Reino de Valencia.

Palabras clave: Manufactura textil, siglo $\mathrm{XV}$, comercio comarcal, artesanado, prosopografía.
JOAQUÍN APARICI MARTÍ Departament d'Història Medieval Universitat de València
Abstract: Onda, a locality with an oscillating population between 300 and 600 dwellings in the 15th century and with Moslems and Jews in the local work, becomes a new piece of the puzzle that lets us see the capillarity of the wool textile manufacture in "La Plana de Castelló". This capillarity can be seen in the production of clothes, just like in the raw material trade or in the movement of craftsmen. To approach this situation we have basically used the series of documents of the judge of the village kept in the "Archivo del Reino de Valencia”.

Keywords: Textile manufacture, 15th century, regional trade, craft industry, biographies.

SUMARIO.

1. Por doquier, la capilaridad.- 2. Manufactura textil lanera en Onda.- 3. Estudio prosopográfico.

\section{POR DOQUIER, LA CAPILARIDAD}

En el siglo XV, el marco geográfico de la Plana se caracterizaba por la existencia de un importante número de poblaciones de pequeño y mediano tamaño, del orden de los 100 a 500 fuegos fiscales de media aproximada, en algunos de los cuales convivieron individuos de las tres religiones del libro. Desde la conquista cristiana del territorio en el siglo XIII se esgrimió la potenciación, en ocasiones, de unos espacios específicos en detrimento de otros, de acuerdo a las necesidades de los conquistadores, pero supuso 
también y de forma paralela una progresiva regresión de la población de origen musulmán que gradualmente se verá superada en número por el continuo aporte cristiano y la migración hacia el sur (Granada o el norte de África). A pesar de ello, la tupida red de núcleos de la Plana mantuvo unos índices de población considerables, y aún cuando la recesión de mediados del siglo XV afectó negativamente a su demografía, los mecanismos internos de redistribución de la población provocaron que la Plana fuese una comarca revitalizada con movimientos a la vez complementarios y contradictorios. De entre todas esas poblaciones sobresalía por importancia demográfica, y también por su función política, la villa de Castelló, si bien en su entorno inmediato, otras tantas poblaciones adquirían un papel complementario decisivo: Vila-real, Onda, Almassora, Nules, Borriol, las alquerías de Uixó, Betxí, etc... Aunque tradicionalmente, la historiografía ha hecho especial mención al desarrollo económico de esta zona basándose en factores tales como la agricultura y la ganadería, observando a su vez la estructura social desde ese punto de vista, la realidad socio-económica de estas poblaciones era algo más específica y diversificada, localizando en la documentación un importante contingente de individuos dedicados al sector secundario y al comercio, que dotaba a estas villas de un matiz interesante para escrutar mejor los nuevos vectores de su economía en el transcurso de dicha centuria.

Uno de esos vectores fue el establecimiento de una especie de circuito comercial y de transferencias mutuas que interrelacionaba a cada una de las poblaciones con el conjunto. Las continuas transacciones a nivel cotidiano establecidas entre los vecinos de un núcleo, y entre éstos y los de las poblaciones cercanas, unidas a la codificación de otras manifestaciones de tipo comercial que servirán para reunir, en un determinado espacio de tiempo, a las gentes de las respectivas esferas de influencia, creará un entramado que aparecerá articulado desde las instancias del poder a través de una jerarquía zonal con la concesión de privilegios sobre ferias y mercados, que entrará en clara conjunción y complemento con los tráficos marinos, las rutas terrestres, y las incipientes manufacturas locales. La Plana tuvo su propia jerarquía interna en ese sentido, pero a su vez quedó integrada en una red superior que la enlazaba con la ciudad de Valencia, y por ello mismo con los intereses de sus mercaderes y de los italianos allí afincados. A la integración de los circuitos locales entre las villas próximas se superpuso esa esfera global dirigida por la capital del reino que consideró el traspaís como un espacio operativo donde se conseguían, y también se distribuían, materias primas y manufacturas, y donde el capital y los artesanos locales tuvieron la posibilidad de participar de la expansión económica del siglo XV. Merced a ello, esta zona, la Plana de Castelló, se convirtió a lo largo de dicha centuria en una especie de "polo de desarrollo industrial", donde cada una de las villas afianzó una serie de producciones artesanales que consolidaron esos "otros vectores" de su economía local. Denominaciones de oficio cada vez más abundantes y con nomenclaturas más variadas, localización geográfica de zonas productoras de materia prima y zonas productoras de manufacturas, y las relaciones entre productores y consumidores, son una constante en la documentación. Y de 
entre esas manufacturas que nos permitan acercarnos y comprender mejor el global de la economía de la zona, la industria textil fue, con toda seguridad, la más importante y difundida, impregnándose de forma capilar en el conjunto de la Plana ${ }^{1}$.

Así por ejemplo, en la villa de Castelló, se documenta la producción cerámica (con artesanos, hornos y "cantererias"), se localiza un horno para vidrio y varios "vidriers", y se cuantifica un número considerable de otros artesanos como los herreros, carpinteros, maestres de obra, etc. Pero a pesar de ello fue la producción de cueros el elemento decisivo que activó económicamente el sector secundario, ya desde finales del siglo XIV, con unas ordenanzas propias y un elevado número de artesanos dedicados a esos menesteres. Con todo, el proteccionismo de la capital del reino marcó el inicio de la decadencia de ese sector en Castelló a mediados de la siguiente centuria, como puso de manifiesto la propia villa de la Plana que se quejó de las pérdidas económicas, y sobre todo demográficas, que la prohibición de entrar cueros acabados en la capital del reino podía provocar en esa villa, pues casi la totalidad de su población se dedicaba a su producción. Desatendidas sus quejas, Castelló tuvo que replantearse su situación, y en la documentación se esboza una especie de reconversión industrial, observándose progresiva y paralelamente a la disminución del número de zapateros y curtidores, el espectacular aumento del número de artesanos dedicados a la producción de paños; la conversión de antiguas curtidurías en tintorerías; la existencia de una cofradía de pelaires, con la participación de éstos en el poder local; la atracción de artesanos de otros lugares; la concreción de un segundo molino batán en la población; y las conexiones, generalmente subordinadas, de las villas cercanas ${ }^{2}$.

También las poblaciones cercanas de Vila-real y Almassora quedaron integradas en el circuito de la producción textil, documentándose ampliamente en la primera de esas villas una situación similar a la de Castelló. Así, en Vila-real se localizaron numerosos artesanos de las más diversas manufactu-

${ }^{1}$ Cọn un carácter más específico sobre la zona de estudio, enunciando ciertas pautas y vías de investigación, véase German NAVARRO y David IGUAL, Les viles medievals de la Plana: nuclis d'activitats artesanals $i$ mercantils, "III Congrés d'Història i Filologia de la Plana" (1992), pp. 63-83. D. IGUAL y G. NAVARRO, Artesanos y mercaderes. De la producción manufacturerá al comercio, "Historia de Castelló", I, (1993), pp. 250-255. Para el caso concreto de Castelló véase la tradicional obra de José SÁNĆHEZ ADELL, Castellón de la Plana en la Baja Edad Media. Castelló, 1982. Una perspectiva amplia, englobadora en Paulino IRADIEL, L'evolució economica, "Història del P. Valencià". II, (1989), pp. 267-324. Una de las últimas aportaciones sobre capilaridad en la zona de la P̉lana en Pau VÍciano, Marché du crédit et structuration de l'espace rural: le Pays Valencien au XVe siècle, "Histoire et Sociétés Rurales", 21 (2004), pp. 11-38.

${ }^{2}$ Para el caso de Castelló, véase fundamentalmente P. IRADIEL, D. IGUAL, G. NAVARRo y J. APARICI, Oficios artesanales y comercio en Castelló de la Plana (1371-1527), Castelló, 1995 , pp. Congrés d'Història i Filologia de la Plana”, Nules (1998), pp. 155-178. En esta localidad se prosopografiaron hasta 196 personas vinculadas directamente con la producción textil lanera, destacando 95 pelaires, 74 tejedores, 16 tintoreros, etc... Sabemos además de la existencia de un batán en funcionamiento desde 1470, y de la construcción de otro en 1494, a petición de Joan Santalínia, pelaire que será jurado de la villa. Añadimos también 8 referencias documentalees a diversas tintorerías, y otras 8 a patios de tirador para extender los paños, así como comercialización de tintes, lanas y paños con las poblaciones del entorno, con las del Maestrazgo, y con la propia ciudad de Valencia. 
ras, destacando en número aquellos de la producción de cueros (con varias curtidurías), pero nuevamente por encima de éstos, la industria textil ofrece un panorama dominante, con un mayor contingente de individuos dedicados a esta actividad, con la existencia de una cofradía de tejedores, de varias casas de tintes, y de dos molinos batanes ${ }^{3}$. Mientras en Almassora, como actividades secundarias importantes se documentaron la producción cerámica, y nuevamente la textil. En dicha población se localiza desde 1396 la existencia de un molino batán sito en la acequia mayor. En el transcurso del siglo XV se menciona en varias ocasiones dicha edificación (1469 y 1480), precisamente indicándose que hacia él confluían los paños de Castelló, lo que motivó la petición de los pelaires castellonenses para la concreción física de un segundo batán en su localidad. Interesantes resultan ambos documentos por cuanto el primero habla de la compra-venta entre tres individuos, cada uno de una población (Vila-real, Almassora y Castelló) lo que permite hablar nuevamente de conexiones locales y capilaridad económica en la zona. El segundo permite la localización toponímica del molino batán sito en la partida de Benafalit, junto a 3 hanegadas de tierra, además de tratarse de una compra-venta de la mitad del batán entre varios pelaires ${ }^{4}$. Además, en relación a la capilaridad y complementariedad existente entre estas villas observamos el trasvase de

${ }^{3}$ Para el caso de Vila-real véase una primera aproximación en M. GUAL, Para un mapa de la industria textil hispana en la Edad Media, "Anuario de Estudios Medievales", 4 (1967), pp. 158159, y J. APARICI, Producció manufacturera i comerç a Vila-real (1360-1529), Vila-real, 1996, pp. 80-89. En esta localidad se localizaron hasta 52 pelaires, 20 tejedores, 16 tintoreros, y.otros muchos con oficios oscilantes. A su vez se recogen toda una serie de disposiciones municipales que pretendían ordenar la actividad textil, ordenanzas fechadas al menos desde 1326 , y relativas a los trabajos específicos de "cardador" de lana, "pentinadors, perayres y tejedors" Algo más tarde, en 1395 se menciona la existencia de una cofradía de tejedores. Estos oficios textiles acabaron quedando reglamentados en un libro, "les ordinacions dels tejedors e perayres", que el "mostassaf" municipal custodiaba ya desdẹ 1414. Según la documentación consultada, los artesanos de la villa se abastecían de materia prima (lanas y productos tintóreos) a traves de mercaderes afincados en Castelló y en Valencia. Además, el desarrollo de esta actividad condicionó la existencia de algunas infraestructuras básicas para la producción y definición de los paños. Así, sabemos del tinte de Nadal Colivella, sito en el arrabal de Valencia (1412). Este mismo espacio, ahora propiedad dẹl tintorero Domingo Querol, sirvió para crear en 1434 una compañía de tintes. A inicios del siglo XVI se documentan dos tintes diferenciados (el de Joan de Ratonina y el de Nicolau Armengol). Finalmente, también documentamos la existencia de varios molinos batanes. Ya en 1314 Jaume II confirmó la licencia otorgada por el Batle General a favor de Guillem Redondo, mercader de Valencia, para poder construir un molino emplazado desde el barranco de Ratils hasta el torrente de Mascarell, bien fuera harinero o pañero. Su concreción física queda definitivamente delimitada en 1502, cuando el oficio de pelaires pida su construcción, ubicándolo en el molino d'en Reus, ingenio que aparece documentado al menos hasta 1527. Paralelamente se documenta otro molino pañero propiedad del notario Bernat Cortés en 1507.

${ }^{4}$ Para el caso de Almassora véase D. IgUAL, Almassora a la Baixa Edat Mitjana: comunitat rural, espai agrari i dinamisme social, "Boletín de la Sociedad Castellonense de Cultura" 75 (1999), pp. 533-560. J. APARICI, La manufactura y el comercio medieval en la Plana. Una contextualización a través del caso de Almassora, "La Murà. Revista del Museu Municipal d'Almassora" (1999), pp. 97-100. En 1396, y sitụado en la acequia Mayor, existía un caserón que albergaba dos molinos harineros y un batăn, siendo arrendatario de este último y de uno de los harineros Alamany Albinyana, persona de importante linaje en la población. Este molino batán tal vez sea el mismo que se loçaliza años más tarde, en febrero de 1469, en el pago parcial del precio de "medietatis pro indiviso cuiusdam molendini draperii", sito en Ảlmassora, entre Mateo Cardona de Vila-real, Bartomeu Sancho de Almassora y Gabriel Vilagrasa, de Castelló. Testigo del acto fue el pelaire de Almassora Pere Lombart. Sobre los Albinyana, véase D. IGUAL, Esglèsia i societat a Almassora (1245-1489), "La Murà, revista del museu municipal d'Almassora" (1999), pp. 1-38. El dato de 1469 en Archivo de la Catedral de Segorbe (ACS), prot. no 711, vol. 4 (1469 febrero 17). El de 1480 en Archivo Protocolos del Patriarca de Valencia (APPV), prot. no 23901 (1480, febrero 21). 
recursos humanos, saber técnico y materias primas. Por un lado conocemos el avecindamiento en Castelló de los pelaires de Almassora Miquel Marco el menor (2 de agosto de 1483) y Pere Lombart (19 de octubre de 1476) ${ }^{5}$. Por otro lado algunos habitantes y artesanos de Almassora buscan en Castelló las herramientas o materia prima (lana o tintes) necesarios para su producción, caso de Pere Ribes, de Almassora, que en 1440 se obligaba con na Jacmeta, de Castelló, en 50 ss precio de "unes tesores de baxar" que le compró. O cuando el pelaire Pere Lombart en 1447 se obligó con el mercader castellonense Francesc Miquel en 6 libras 10 ss precio de lana que de éste había adquirido $^{6}$. Finalmente, el rastreo posopográfico sobre artesanos realizado en diversos archivos y tipologías documentales ofrece una reducida nómina de individuos dedicados a la producción textil durante el siglo $\mathrm{XV}$, a saber 8 pelaires, 1 tejedor y 4 "pilaters de molí"?

La inmersión de este sector productivo en la dinámica económica de las poblaciones de la Plana se percibe en algunos más de los núcleos mencionados, si bien la precariedad documental hace que sean meras referencias, en ocasiones anecdóticas, pero necesarias para tratar de establecer parámetros de interpretación. Así por ejemplo, sabemos de la existencia de otro molino batán en Vilafamés ${ }^{8}$, una casa de tintes en Alcora ${ }^{9}$, y de algún

\footnotetext{
${ }^{5}$ Archivo Histórico Municipal de Castelló (AHMCs), libro de avecindamientos n ${ }^{\circ} 1$ (14391567).

${ }^{6}$ AHMCs, justicia obligaciones $n^{0} 12$ (1440, julio 14), obligaciones $n^{\circ} 14(1447$, septiembre 12). En 1448 Joan Jacqués, de Almassora se obligaba en pagar al mercader castellonense Berenguer Castell 7 libras precio de lanas. En 1495 el notario de Castelló Antoni Valentí instó judicialmente contra Pere Pintor, de Almassora, para que le pagase los 60 ss 4 dd debidos de precio de lana que le compró. ÁHMCs, justicia obligaciones n 15 (1448, mayo 20), letras $n^{\circ}$ 20 (1495, agosto 21). Por lo que respecta a los tintes, Tas noticias son más fortuitas. Sabemos que en 1466 el mercader castellonense Guillem Palau instó judicialmente contra la mujer y herederos de Jaume Pintor, de Almassora, pidiéndoles que pagasen las 18 libras debidas por Jaume, razón de tintes. A su vez Palau también pedía asignación de días al pilatero Antoni Montull, de Almassora, para que quitase las "set alnes de calçats e hun palm de verts clars e quatre alnes e un palm de calçats blanchs ab una alna burella en lo dit tros, tot en una peça", que el mercader tenia como garantía del pago de 35 ss 8 dd debidos de tintes. Véase AHMCs, justicia n ${ }^{\circ} 16$, letras (1466, octubre 2).
}

${ }^{7}$ Los pelaires son Pere Lombart (1447-1476), Francesc Miquel (1466), Antoni Peris (1473 1474), Antoni Balaguer (1480), Antoni Monsoriu (1478-1480), Pere Sanxo (1481), Miquel Marco el menor (1483), Antoni Ferrer (1484). El tejedor es Joan Montsó (1453). Los pilateros de molino batán son Antoni Montull (1466), Pere Sancho (1478), Bartomeu Micó (1484-1500) y Joan de la Cort (1527). Véase D. IGUAL, Almassora a la Baixa Edat, op. cit, pp. 533-560; y J. ÁPARICI, La manufactura y el comerç, op. cit, pp. 81-108.

${ }^{8} \mathrm{El}$ establecimiento de un molino harinero o batán en Vilafamés, junto a la Rambla de la Viuda, el 6 de mayo de 1320, mediante licencia otorgada por el maestre de Montesa a favor de Domingo Forcadell, con la condición de fijar su residencia en Vilafamés o su término, debiendo estar construido antes de Navidad de 1321. Un año después, el 7 de mayo de 1321, Ârnau de Soler, maestre de Montesa autorizó a los hombres de Cabanes para poder coger grana en término de Vilafamés por ese año. Carles RABASSA y Carmen DIAZ, Documents per a la Història de Vilafamés, Castelló, 1995, pp. 58-60. También el 1 de agosto de 1429. Berenguer Rabades, tejedor de este lugar, se avecindó en Castelló por tiempo de 10 años. AHMCs, compres-vendes, 1b, f. 30r.

${ }^{9}$ La casa de tintes de Alcora fechada en 1305, en M. GuAL, Para un mapa de la industria, op cit, p. 122. Documentamos la compra de materia prima por parte de habitantes de esta población, no sabiendo por ahora si está destinada al consumo propio o a la redistribución. En 1416 Domingo Sanxis Navarrọ, de l'Alcora se obligó en pagar al mercader castellonense Manuel Caxa 61 florines $1 \mathrm{~s} 3$ dd precio de lana que compró. El acto se canceló un año después. Localizamos a su vez el avencindamiento de un tejedor de l'Alcora en Castelló en 1456, Mateu Tarragó. AHMCs, justicia $n^{0} 1$, obligaciones (1416, noviembre 2); libro de avecindamientos (1456, 
artesano del ramo textil en las alquerías de la Vall d'Uixó ${ }^{10}$, y en las villas de Burriana $^{11}$ y Nules ${ }^{12}$.

Situación similar es la que documentamos también en otra comarca castellonense, la del Palancia ${ }^{13}$, con un núcleo central, político, religioso y económico como es Segorbe ${ }^{14}$, y la capilaridad que se percibe respecto a las localidades próximas, caso de Jérica ${ }^{15}$, $\operatorname{Viver}^{16}$, Bejís $^{17}$, Altura ${ }^{18}$ o

diciembre 23).

${ }^{10}$ En Vall d'Uixó, los mudéjares Hamet Gona y Alí Alzuever compraron, el primero el 13 de julio de 1486 a Agostino da Ponte, y el segundo el 27 de abril de ese mismo aṇo a Corrado da exterior en el segle $X V$. L'activitat mercantil una italiana a. la Plana, "Economia local i comerc Filologia de la Plana", Nules (1998), pp. 113-138.

${ }^{11}$ En Burriana, entre 1420 y 1430 documentamos al tintorero Jaume Fababuix. En 1420 era requerido como testigo en un acto judicial. Mientras, el 13 de febrero de 1430 se obligó en pagar al mercader de Castelló Berenguer Moliner 28 ss 2 dd precio de una carga de pastel, cancelándose el acto el 19 de febrero de ese mes, y obligándose en julio con el mismo mercader en 60 ss por otra cantidad indeterminada de pastel, cancelándose esta obligación el 7 de agosto del mismo ano. En 1499 se avecindó en Castelló el pelaire burrianense Antoni Ferrer. AHMCs, justicia n ${ }^{0} 3$, actos comunes (1420, noviembre 20), justicia $n^{\circ} 10$, obligaciones (1430, febrero 13; julio 18), libro de avecindamientos (1499, enero 3 ).

${ }^{12}$ También en Nules encontramos algunos artesanos del sector texṭil, como el pelaire Batiste Adzuara (Archivo del Reino de Valencia, ARV, prot. 1449; 1509, juniọ 28), o el también pelaire Ambrosi Tolra (APPV, prot. 22756; 1513 , noviembre 24), que participan en compra-ventas de tierra; el pelaire Gabriel Simó, que se obligó en pagar a la donataria testamentaria del difunto maestro tintorero de Castelló Miquel Alberich, $36 \mathrm{ss}$ de tintes debidos (AHMCs, justicia no ${ }^{0}$ 1, oblig; 1511, septiembre 7). También localizamos el avecindamiento por 10 años en Valencia de algunos artesanos, como el pelaire Pere Camarassa, el 24 de abril de 1437 en la P. S. Joan del Mercat, calle dels Carnicers; o Jeroni Tremunt, pelaire, el 12 de junio de 1514 , en la P. S. Joan. El primero en L. PILES La repoblación de Valencia a través de los llibres de avehinaments (14001449). Valencia, 1978. El segundo en Archivo Municipal de Valencia (AMV), avecindamientos b3-10, f. 162 r.

${ }^{13}$ Tómese como base de referencia documental para cada una de las notas que siguen sobre las poblaciones del Alto Palancia el trabajo de J. APARICI, El Alto Palancia como polo de desarrollo económico en el siglo XV. El sector de la manufactura textil. Segorbe, 2000. Interesante resulta también el estudio de una célula familiar artesana en descomposición por la muerte del padre, un tejedor. Véase J. APARICI Y G. NAVARRO, El libro memorial de la tutela del tejedor Joan Fretero (Segorbe 1432-1440), "Estudis Castellonencs", 7 (1996-97), pp. 231-264.

${ }^{14} \mathrm{Se}$ localiza habitando en la ciudad episcopal durante todo el siglo XV y primera década del XVI a un total de 253 pelaires, 64 tejedores, 23 tintoreros, y hasta otras 50 personas con oscilaciones de oficio. A su vez en Segorbe se documentan contratos de aprendizaje relacionados con el oficio textil. Por lo que respecta a las infraestructuras productivas, se documentan varios obradores en manos artesanas, algunos tiradores ubicados en el arrabal de la ciudad, la existencia de dos molinos batanes en funcionamiento entre 1440 y 1467 , continuando al menos uno de ellos hasta 1515 , situados ambos en la partida de Los Moliniéllos, "camí. per quod tenditur ab monasterium Vallis Jhesu Crhisti, prope rivuum dicte civitatis Sugurbi". Disponemos de los contratos de arriendo de estos batanes, propiedad de la oligarquía de la capital del reino o de la nobleza del entorno, arrendados a varios pelaires de la ciudad episcopal. Por su parte, también existen en funcionamiento al menos dos casas de tintes diferenciadas. Disponemos de datos sobre ellas desde 1401 hasta 1501 . También para Segorbe disponemos de varias referencias al arrendamiento del cobro del "Tall del drap" en la ciudad y su "quarter" (1503 y 1514).

${ }^{15}$ Aunque Segorbe sea el verdadero centro poblacional y manufacturero de la comarca del Alto Palancia, el resto de poblaciones recogen el testigo de la capilaridad del crecimiento económico determinado, en parte, por la manufactura textil. En Jérica hemọ localizado la nada desdeñable cifra de 57 personas vinculadas con este sector, a saber 44 pelaires, 7 tejedores, 2 tintoreros, 1 bajador, 1 pelaire-tejedor, 1 tejedor-"flaçader", y 1 maestro cintero. Con la excepción de 2 pelaires, el resto aparecen concentrados en la segunda mitad del siglo XV e inicios del XVI, posiblemente síntoma de un mayor desarrollo de esa actividad en esos momentos (si bien esta apreciación puede estar distorșionada por una relativa mayor abundancia de fuentes escritas para ese período). También en Jérica se documentan contratos de aprendizaje del oficio textil. A su vez se documentan infraestructuras productivas del sector, tales como los patios de tirador, o los tintes y molinos batanes. Respecto a estos últimos, en 1376 el infante Marti y su esposa María de Luna donaron a mosén Bonafonat de Sent Feliu, además de dos molinos harineros y otros bienes, el molino batán de la villa de Jérica, y el tinte ubicado en dicha población. En 1403, Bernat, hijo 
Castellnovo $^{19}$. De la misma manera tuvimos la ocasión de comprobarlo para el caso de las vecinas tierras de Teruel, con la propia ciudad al frente, pero también con un nutrido grupo de pequeñas poblaciones donde esa actividad textil se ponía de manifiesto ${ }^{20}$.

Como veremos a continuación Onda, en el contexto de la Plana de Castelló, participó de esa dinámica, del trasiego de profesionales, del intercambio de materia prima o producto acabado, con un significativo número de artesanos, con la participación activa de las minorías religiosas, la existencia de algún molino batán y casa de tintes, o también con la relación establecida con los mercaderes italianos afincados en Valencia. Por ello Onda

de Bonafonat, recibió permiso del rey para poder vender el tinte y el molino batán a favor de los síndicos de Jérica, Viver, Caudiel, Benáfer, Novaliches, Barracas y El Toro, que los compraron por un precio de 9000 ss, lo cual implicaría posiblemente una inicial gestión conjunta, pero también una centralización de la producción en dicha villa donde se llevarían a término los trabajos de definición con el abatanado y tintado de los paños producidos en los otros pequeños lugares. Posiblemente ese mismo batán sea el que en 1407 documentamos en manos del pelaire de la villa Nicolau de Signa, quien pedía poder hacer un azud en el río para poder recoger agua para dicho ingenio. La continuidad y existencia en Jérica de ese ingenio en manos de profesionales de la actividad textil queda patente en 1491 cuando entre los bienes inmuebles de Elvira, viuda del pelaire Bartolomé Domingo, se consigne la existencia de "hụn molí traper", mientras entre los muebles destacaban numerosos útiles del oficio de pelaire, así como materia prima. Documentamos a su vez en 1454, 1479, 1484 y 1490 el arrendamiento del derecho a percibir el "Tall del Drap" en esta población y los lugares de su término.

${ }^{16}$ Situada muy próxima a Jérica, se localizan en ella a 12 pelaires, 1 pelaire-tejedor, y otros tres individuos que aparecen indistintamente como vecinos tanto de Jérica como de Viver, cuyos oficios son 1 tejedor-"flacader", y 2 pelaires, concentrados homogéneamente todos ellos desde los años 40 del siglo XV hasta las primeras décadas del XVI. También aquí documentamos infraestructuras productivas, como el molino batán. En marzo de 1407 parece ser que en este lugar se estaba procediendo a la construcción de un molino batán por parte del procurador del senor de dicho lugar en contra de ciertos privilegios pertenecientes al monasterio de Vall de Crist, y que impedían nuevas edificaciones de tales ingenios. Con todo, documentamos en 1468 la existencia de un batán en funcionamiento propieđad del señor de Jérica y de los lugares de su tenencia, Francisco Sarsola, cuyo procurador lo arrendó a los pelaires de Viver Joan Martín y Bartolomé y Mateo Bas ("un molino trapero del muy magnífico mi senyor... situado en el prado nombrado del Agua Blanca, frente a la acequia Mayor del agua Blanca"), por tiempo de 3 años y precio de 80 ss por anualidad.

${ }^{17}$ En Bejís localizamos a 5 pelaires entre los años 40-70 del siglo XV (Bernat Durán, Pero Oller, Joan Pérez, Domingo Polo, Jaime de Sos). Como infraestructura productiva documentamos la existencia de un molino pañero en 1406, gracias a una venta de tierras en la partida del Almargal, uno de cuyos lindes era con la acequia de dicho molino. A ello unimos que en mayo de 1452 se establecía un reconocimiento de deuda por la compra-venta de un molino pañero valorado en 600 ss, hecha entre el pelaire Domingo Polo y un vecino del lugar. Pero parece ser que existían dos ingenios diferentes, pues en julio de ese mismo año un pelaire segorbino, Joan Aragonés, vendió por 250 ss al pelaire de Bejís Bernat Durán la mitad de "hun molino trapero situado dins la regatiella", que afrontaba con el río y con acequia, el cual estaba bajo señoría de la Orden de Calatrava a censo de 40 ss anuales. También se documenta para los años 1449, 1468 y 1484 el arriendo del cobro del "Tall del Drap" en esta población.

${ }^{18}$ En Altura se documenta a 3 tejedores en la primera mitad del siglo XV (Domingo Balsa, Pero Sales, Martín Sánchez) y a 6 pelaires en la segunda mitad de dicha centuria (Pere Çalom, Nadal de Daroca el joven, Antoni Guayta, Joan Março, Peral de Monlleó, Joan Nicolás). Como infraestructura productiva documentamos la existencia en 1507 de un molino batán propiedad de los frailes de Vall de Crist, molino que sufrió cierto perjuicio cuando el pelaire que allí trabajaba, el segorbino Francesc Tortajada, ordenó al mozo de su padre que le ayudaba, que cerrase el paso de agua, con lo que el molino cesó, durante un tiempo, su actividad.

${ }^{19}$ En esta localidad de población mixta se documenta a dos pelaires cristianos (Blai Gonçalves entre 1504-1538 y Gaspar Tortajada entre 1480-1508) y dos tintoreros mudéjares siendo uno propietario de un obrador en Segorbe (Alí Alabib en 1415 y Jucef Alabib entre 1421-1443).

${ }^{20} \mathrm{G}$. NAVARRO y J. APARICI, La industria textil en el Teruel medieval, "Teruel", 88-89 (20002002), pp. 73-100. Ún ejemplo particular queda recogido por ambos autores en Villarluengo, un lugar de la bailia de Cantavieja en el siglo XV, "Aragón en la Edad Media”, XX (2008), pp. 543-558. 
se convierte en una pieza más del puzzle de relaciones comerciales de corto y medio radio de ámbito comarcal, y completa un poco más si cabe el mapa de la producción de manufacturas que estamos reconstruyendo para el norte del reino medieval de Valencia $^{21}$.

\section{MANUfaCtura TEXTIL LANERA EN ONDA}

Geográficamente, Onda aparece situada en un emplazamiento estratégico para aprovechar las corrientes comerciales generadas en su entorno, pues la villa está asentada entre los márgenes de la Plana y las estribaciones montañosas de la Serra d'Eslida y Espadà, al lado del río Millars que abre el camino hacia el interior, concretizando su actuación como centro productor y redistribuidor en un cinturón agrario que la circunda. Como si de una cuenca vertiente se tratase, las poblaciones ubicadas en la inmediata zona montañosa (Sueras, Ahín, Veo, Fanzara, Toga, etc...) o las alquerías de su propio término (Tales, Ribesalbes, Artesa) tienen en Onda el principal punto de referencia comercial y manufacturero. A continuación encontramos otros núcleos cercanos, de mayor entidad demográfica (Betxí, Nules, Vila-vella o Vila-real), que establecerán una especie de segundo círculo concéntrico y que mantendrán habituales y continuos contactos con Onda, seguidas a distancia por Castelló. Finalmente, como punto focal último, la capital del reino, la ciudad de Valencia, será un referente obligado en la amplia red de este circuito comercial $^{22}$. En este entramado, la circulación de lanas, tintes y paños será un elemento significativo del global de intercambios.

La primera de las noticias que nos permiten hablar del desarrollo de la manufactura textil en Onda se remonta a la mención de la caldera de tintes en la carta pobla de 1248 y al año 1320, cuando según el inventario de bienes y rentas que la Orden de Montesa tenía en la villa, se hace mención a un tinte arrendado por 310 ss anuales. También a fines del XIV se documentan algunos permisos del maestre para establecer telares en casas de la localidad ${ }^{23}$.

Sin embargo, y condicionados por la documentación, no es hasta el siglo XV cuando podemos escrutar mejor el panorama. Así, el desarrollo de la ganadería fue un elemento clave para atender, no sólo al carácter alimenti-

\footnotetext{
${ }^{21}$ Los datos localizados para Onda proceden de un muestreo específico realizado en algunos volúmenes del justicia de Onda localizados en ARV, sección bailía general. Dichos libros han sido vaciados exhaustivamente compilando todos los artesanos documentados. La cata ha sido aleatoria y se han escogido libros de principios del siglo XV, otros de la década de los 70 , y uno de 1500 1501. Proyecto GV/2009/042, de la Generalitat Valenciana (I +D) "La manufactura rural i els oficis artesans en les comarques septentrionals valencianes durant la Baixa Edat Mitjana", desarrollado en la Universidad Jaime I de Castelló.

${ }^{22} \mathrm{~J}$. APARICI, Conexiones comerciales de corto radio entre Onda y las morerías cercanas en el transcurso del siglo XV, "Butlletí d'Estudis Municipal", 2 (1999), pp. 107-126. De hecho, se descubre claramente la existencia de dos áreas de influencia bien diferenciadas en la Plana al contraponer el radio de acción de Onda descrito en este trabajo, comparándolo que el área localizada por P. VICIANO, Marché du crédit, op. cit, pp. 11-38.

${ }^{23}$ Enric GUINOT, Feudalismo en expansión en el norte valenciano. Antecedentes y desarrollo del señorío de la O'rden de Montesa. Siglos XIII y XIV. Castelló, 1986, pp. 224-225, nota 70.
} 
cio de la población, sino también al manufacturero. Pieles y lanas fueron dos materias primas ampliamente demandadas que generaron corrientes de intercambio importantísimas entre el reino de Valencia, las tierras de Teruel, y también Italia ${ }^{24}$. La potencialidad ganadera en tierras de Castelló fue inmensa, y por ello, las aproximaciones parciales o locales configuran mejor el conocimiento sobre unas cabañas que, practicando la trashumancia de medio radio, permiten al investigador acercarse al mercado lanero local o regional, articulado generalmente a través de pequeñas transacciones en las que se movían modestos capitales y cantidades de materia prima. Así pues, sabemos que merced a la cabaña ganadera autóctona, en esta villa se podía obtener parte de la lana que pudiera precisarse para la producción local. Si bien resulta imposible cuantificar el volumen global de la misma (salvo en el censo de 1510), sí podemos indicar que los rebaños ondenses practicaban la trashumancia hacia tierras de Teruel, y que tanto los cristianos como los mudéjares fueron propietarios de cabezas de ganado. En 1437, Aparici Gallén, vecino de Puerto Mingalvo se obligó en pagar a Martí Pexó 18 ss por ciertos daños que su rebaño le había hecho en su tierra de cereal situada en el río Millars. Poco más tarde, el mudéjar de la alquería de Tales, situada en término de Onda, Cilim Marchich indicó al justicia de esta villa que "havia e tenia franquea e en virtut de la qual era franch en tot loch de la senyoria del senyor rey d'Aragó de leuda, pes, messuratges", exponiendo que "ell venint camí caminant del loch de Linares ab lo seu bestiar”, en Toga fue requerido para pagar el "passatge", haciéndose caso omiso a su franquicia".

En un marco como éste, donde el ganado formaba parte de la economía de los habitantes del lugar, las compra-ventas de lanas se hicieron constantes, poniendo en contacto a los productores con los artesanos. En 1423, el pelaire ondense Joan García confesó deber al también ondense Jaume Pexó 147 ss 5 dd precio de ciertas lanas. Pero debemos tener presente que el circuito de intercambio se amplió, capilarmente, a otras poblaciones. En 1412, Batomeu de Casseda, vecino de Onda se obligó en pagar a Joan Nicolás, vecino de Villamalur, 320 ss precio de 20 arrobas de lana a razón de 16 ss cada una, más otra arroba y media de “anyins, al terç d'aquella”. En 1448, el pelaire-tintorero Francesc Llobregat reconoció cierta deuda, precio de lana,

\footnotetext{
${ }^{24}$ Como introducción véase el tradicional estudio de Enzio LEVI, I fiorentini nel Maestrazgo al tramonto del Medievo, "BSCC", 10 (1929), pp. 17-29. C. RABASSA, El comercio de lana, "Historia de Castellón", I, 1993, pp 246-249. Con todo, resulta fundamental la lectura del estado de la cuestión en D. IGUAL, Valencia e Italia en el siglo XV. Rutas, mercados y hombres de negocios en el espacio económico del Mediterraneo Occidental, Castelló, 1998.

${ }^{25} \mathrm{ARV}$, bailia general n ${ }^{\mathrm{o}} 1307$ (1437, mayo 10; septiembre 12). En el censo de 1510 aparecen contabilizadas 2202 cabezas, siendo sólo una quinta parte propiedad de cristianos. Las restantes cuatro partes se distribuían del siguiente modo: 3 familias de mudéjares de Onda poseían 341 cabezas. 11 mudéjares de Artesa eran propietarios de otras 468 cabezas, y 7 vecinos de Tales eran propietarios de otras 932 cabezas. Véase Vicent GARCÍA, Aproximación al marco económicosocial de las morerías del castillo de Onda durante los siglos XIII a XV, "IV Simposio Internacional de Mudejarismo", Teruel, 1992, p. 344. Otros datos complementarios: sabemos que en 1472 Jaume Luca de Onda se obligó en pagar a Mafomat Axufí mudéjar de Sueras 35 ss 6 dd razón de bestiar. En 1474 Pere Molinos de Onda debía 60 ss a Alí Abdurrahmen alias Blanco, mudéjar de Artesa, razón de borregos. ARV, bailia general no 1313 (1472, agosto 17), n ${ }^{\circ} 1315$ (1474, enero 8).
} 
con el mudéjar de Betxí Çuleymen Alcatraç. Años más tarde, en 1495, Francesc Martí, procurador del mercader castellonense Joan Eximeno, instó judicialmente contra el pelaire ondense Joan Marí para que pagase una deuda de $12 \mathrm{lb}$, restantes a pagar de las $16 \mathrm{lb}$ precio de cierta lana ${ }^{26}$.

El proceso de producción, someramente descrito, suponía que antes de llegar a manos de los artesanos, estas lanas eran lavadas y limpiadas para eliminar las impurezas que pudieran contener, y con toda seguridad separadas según sus diversas calidades. Arqueada para que los copos se abriesen, pasaba a manos del "cardador" que las peinaba para igualar las distintas longitudes de las fibras, si bien también cabe la posibilidad de que esta operación fuese realizada por mano de obra no excesivamente cualificada, en muchas ocasiones femenina, que complementaría así su economía doméstica. En esta sentido, el hilado sería realizado posiblemente por esas mismas mujeres, siguiendo una tónica general descrita para todo el reino de Valencia en la Edad Media ${ }^{27}$. Con todo, sabemos que el tejedor Francesc Conca poseía en 1473 , además de su telar y de un "ordidor, un torn de filar ab sos arreus" 28.

Una vez hilada la lana, se preparaba la urdimbre en un "ordidor", como el ya mencionado de Francesc Conca, para poder pasar posteriormente al tejido propiamente dicho. Montada la urdimbre en un telar, la textura, más que las operaciones preliminares o posteriores, será la operación que de al paño sus características esenciales. Nosotros documentamos hasta un total de 10 tejedores, y nuevamente el caso de Francesc Conca, que en 1472 había pagado 60 ss al también tejedor Francesc Scuriola por el precio de un telar.

A continuación se producían ya toda una serie de operaciones encaminadas a conseguir un mejor acabado y presentación del paño, con el limpiado en profundidad del mismo sufriendo la operación mecánica del enfurtido en el molino batán, y también con una homogeneización armoniosa de su superficie, siendo cardado a la percha, procedimiento mediante el cual,

${ }^{26}$ ARV, bailia general $n^{\text {o }} 1306$ (1423, abril 28) y n ${ }^{\text {o }} 1304$ (1412, julio 7). El dato de 1448 en C. DÍAZ, Intercambios económicos de los mudéjares de Onda y su entorno durante el siglo XV "Butlletí d'Estudis Municipal", 1 (1999), p. 151. AHMCs, justicia n ${ }^{\circ} 20$, letras (1495, julio 3. El acto notarial fue ante A. Féliu el 5 de octubre de 1494). En 1417, Joan Loscos de Onda se obligó en pagar al mudéjar de la Alcudia de Veo Abrafim Alí 23 ss precio de lanas. En octubre de ese mismo año, Pere Utriellas de Onda se obligó en pagar al también ondense Joan Gallén 24 ss razón de lanas (ARV, bailia general $n^{\circ}$ 1305; 1417, febrero 18; octubre 5). En 1472, Guillem Sala de Onda se obligó en pagar a Antoni Palomar el' menor, también de Onda, 64 ss precio de un quintal de lana, a razón de 16 ss la arroba (ARV, bailia general, n ${ }^{\circ} 1313 ; 1472$, diciembre 18). En 1476, Jaume Valero de Onda confesó deber a Hamet Çalçe moro de Fanzara 67 ss 6 dd por 5 arrobas de lana (ARV, bailia general no $1317 ; 1476$, junio 28).

${ }^{27}$ Por ejemplo en Orihuela, en un memorial que en 1431 enviaron los jurados de la villa al rey Alfonso $V$ en el que se detallaba la antaño boyante industria textil, ahora en decadencia, se relataba que muchas viudas, mujeres pobres y otras vivían del oficio de pelaire, "hunes filant al torn en lurs cases, e altres a filar stams". Por otro lado sabemos que en 1432 las mujeres segorbinas iban a la morería "per lana per a filar... dones axí fadrines e vídues com casades". Ante las continuas tropelías que para con ellas hacían los mudéjares, el baile general ordenó "que dones negunes no gosen filar stams ni tramas dels dits infels". Véase el primer texto en P. IRADIEL, En el Mediterraneo Occidental peninsular: dominantes y periferias dominadas en la $B E M$ "Areas, revista de Ciencias Sociales" (1986) p. 70, y el segundo en ARV, real cancilleria $\mathrm{n}^{\circ} 625$ (1432, marzo 12).

${ }^{28} \mathrm{~A}$ partir de ahora obviaremos las citas a pie de página que hagan referencia a estos artesanos, invitando al lector a la consulta directa del punto 3 de la presente investigación donde se consignan las referencias prosopográficas a los mismos. 
pelaires o "baxadors", elevaban ciertos pelos del paño y obtenían cierto brillo cuando cortaban, de forma definida, esa pelusilla. En Onda hemos localizado 1 "pilater", 1 "baxador", y hasta 17 pelaires.

El elevado número de pelaires se podría interpretar argumentando la escasa diferenciación de labores existente en el artesanado del ámbito rural, contando en principio con la presencia del oficio más documentado en el control de todo el proceso productivo más allá de las labores que le son propias, distribuyendo las labores como eje central del proceso, o participando y controlando desde las fases primigenias de preparación de la materia prima y abastecimiento de la lana, hasta las fases de definición del paño. En ese sentido, recordemos que los pelaires Joan García, o Francesc Llobregat, compraban directamente las lanas en 1423 y 1448; que en 1473 el también pelaire Ángel Andrés debía cierta cantidad "per texiduries" al tejedor Jaume Andrés, a quien con casi total seguridad había encargado la realización del paño; que en 1472 el pelaire Joan Matamoros se obligaba a pagar a Miquel Benedito "les pilatadures que havia fetes en lo seu molí"; que en 1420 el tintorero Domingo Querol mostró la indefinición u oscilación de su labor, al obligarse "a complir e treballar e usar de son officii de tintorer e de perairia, axí en lo tint del dit Lorenç que té en Castelló", diciendo Querol que allí trabajaría si había labor, y si no que "treballarie com a baxador de draps, tirar e apuntar aquells en casa del dit Lorenç", caso similar al de Francesc Llobregat, cuyo oficio oscila de pelaire a tintorero, o al del pelaire Pere de Casa, que en 1478 compraba pastel a un mercader italiano afincado en Valencia.

Todos los datos apuntados hasta ahora muestran un ciclo que podemos considerar más allá de la simple producción rural, contando con una posición favorable para el abastecimiento de lanas y el suministro de colorantes o materia tintóreas. Estos últimos, tanto en Onda como en otras villas, tendrán un origen foráneo. Aunque numerosos lugares de nuestro territorio muestran la presencia de varias materias tintóreas en su cinturón rural inmediato, el pastel devendrá el elemento colorante más demandado pues resultaba de uso obligado para la obtención de azul, y base para obtener otros colores complementarios. Además, muchos paños crudos recibían un simple tintado en azul para mostrar un mejor acabado. Por ello, en torno a dicho colorante se desarrolló un amplio marco de comercialización, donde generalmente el consumidor directo, el artesano (pelaire o tintorero), contactaba con el mercader que podía suministrarle el cargamento de pastel, generalmente un comerciante italiano afincado en Valencia, conformándose una importante red de distribución en base a compras regulares de pequeñas cantidades ${ }^{29} \mathrm{En}$ nuestro caso, y siguiendo este modelo, sabemos de las compras hechas por los

\footnotetext{
${ }^{29}$ Fenómeno también descrito para la zona de Cocentaina por José A. LLIBRER, Artesanado y formas de organización de la producción textil rural: Cocentaina (1469-1487), memoria de licenciatura Universidad Valencia, 1995, pp 86-95. Para el caso de la Plana véase D. IGUAL, Economia local i comerç, op. cit, pp. 123-126.
} 
ondenses Pere de Casa, Francesc Llobregat y Guillem Sala a varios mercaderes italianos de Valencia.

Entre los artesanos documentamos además un global de 9 tintoreros (uno oscila a pelaire), alcanzando alguno de ellos una promoción social considerable, como Francesc Llobregat o Miquel Péreç que en la primera década del siglo XVI llegarán a ocupar la magistratura municipal de la sindicatura. A falta de más datos prosopográficos sobre estos individuos, la situación es similar a la vivida en Castelló, Vila-real o Cocentaina. Ahora, en el caso de Onda también se deja entrever una cierta gradación social en el seno de la comunidad artesana, que se plasmará a su vez en una clara y distinta posición económica, en la que algunos de sus miembros, como estos dos tintoreros, devendrán personajes reconocidos no sólo en referencia a su oficio, sino también en el conjunto de la villa donde habitan, trazando toda una serie de estrategias que les permitan perpetuarse como miembros y partícipes del poder político y económico local ${ }^{30}$.

En el siglo XV, el impulso de la producción textil debió ser un atractivo importante para facilitar la movilidad de ciertos individuos, artesanos especializados o personas sin cualificación, que buscarían así mejorar, dentro de lo posible, su situación socio-económica. Aún así, debe tenerse en cuenta la complementariedad de los movimientos migratorios, continuos y contradictorios a un mismo tiempo. Así, de Onda marcharon a Valencia el pelaire García Eximeno (1447), y a Castelló los tejedores Domingo Avinent, Miquel Descó (ambos en 1458) y el pelaire Guillem Marco (1456). Unimos otra serie de referencias que hacen mención a ese movimiento, caso de los tintoreros Nicolau Scuriola (1525), que originario de Onda habita en Castelló, o de Domingo Querol (1420), que trabaja en esa última villa. Pero no todo son pérdidas demográficas para Onda. A la villa acudirán otros artesanos con un claro movimiento compensatorio. El pelaire Miguel Bonfill (1500) o el tintorero Bertomeu Morant (1473) declaran ser "comorants", es decir, que están al menos temporalmente en la villa, caso similar al de Joan Venrell (1472), tejedor oriundo de Campos, en la isla de Mallorca; o del musulmán Alí Faraig que, aunque vecino de Toga, trabaja en Onda (1417).

Como vemos, las inversiones en la manufactura textil en la comarca crearon toda una red capilar de contactos que permitieron a algunas poblaciones acrecentar su impulso económico y humano. Los artesanos de Onda precisaron el pastel proporcionado por los mercaderes italianos, y en ocasiones también lanas foráneas; los hombres circularon de un lugar a otro. La importancia de los aspectos de acabado del paño posibilitarán que, además del batán o el tinte de Onda, otros espacios de producción surjan en un marco geográfico inmediato, dentro del propio término municipal de la villa. En 1405 Domingo Ros d'Orsins, señor de Ribesalbes, Berita y Trutxelles concedió su carta puebla indicándose que los mudéjares estaban obligados "a apparellar tots vostres draps en lo molí draper, et tenyir en lo tint quan n'hi

${ }^{30}$ Véase en ese sentido G. NAVARro, Joan Santalinia i altres, op. cit, pp. 155-178. 
haurà tots vostres draps", noticias que nos hablan de una posible producción integrada en la temporalidad de las tareas agrarias desarrolladas por estos mudéjares, con una producción destinada al autoconsumo y tal vez también al comercio de corto o medio radio, inserida en los circuitos de producción y comercialización representados por los artesanos de Onda ${ }^{31}$. Pero Onda a su vez acogerá las necesidades generadas en otros núcleos próximos canalizando hacia ella las posibilidades de trabajo. Ya hemos visto la capacidad de absorción de las lanas del traspaís montañoso (Villamalur, Alcudia de Veo, Fanzara), pero también la villa ofreció la realización de servicios a los habitantes de las villas vecinas. Así, en 1418, el consejo municipal de Vilareal pagó al sastre ondense Pasqual Asensi 18 ss por sus trabajos en hacer ropajes para vestir al sayón. Años más tarde, en 1453-54, y también desde Vila-real era requerida la presencia de un "maestre de tint" de Onda, "per veure e regonèxer una bruneta que fou acusada que ere de tinta falsa". Años después, en 1472, el tintorero de Villahermosa Bertomeu Mollo se obligó con el ondense Pere Casset en 80 ss "per pacte de la companyia que entre aquells ere stada en possar una tina"; o en 1473, cuando el "pilater" Miquel Benedito fue condenado por el justicia en pagar a Çat Hamit, moro de Vila-Vella, 15 ss 4 dd como estimación de las 9 alnas y media de "albadens" que le había encomendado para "adobar de molí, e aquelles serien perdudes" 32 .

Finalmente debemos mencionar que los diversos arrendamientos del "tall del drap" y de "la bulla", elementos de fiscalización de la producción textil, muestran un proceso de afianzamiento de esa producción local que comenzaría, con cierta seguridad, a superar el autoconsumo ${ }^{33}$. La producción textil de Onda posiblemente no estuvo circunscrita exclusivamente al abastecimiento de los propios vecinos de la villa, sino que debió suministrar paños a las poblaciones más cercanas. Difícilmente se sobrepasaría ese mercado, como mostrará el cuadro adjunto. Los sastres de la misma población eran frecuentes compradores de los mismos, y en el muestreo aleatorio se indica que la mayoría de los compradores son ondenses, con la salvedad de algún paño que se vende en Nules, Alcudia de Fanzara, Burriana, o inclusive en Pavías. Además, también los ondenses compran paños a individuos de las poblaciones vecinas, caso de Betxí. Esta producción podemos suponer que fue de una calidad media o baja de acuerdo a los paños referenciados en las compra-ventas documentadas, elemento que entraría en clara sintonía con las conclusiones alcanzadas en otros ámbitos geográficos, como en Cocentaina o

${ }^{31}$ D. IGUAL, J.A. LliBRER, G. NAVARRO, Materias primas y manufacturas textiles en las aljamas rurales valencianas, "VI Simposio Internacional de Mudejarismo", Teruel, 1996, p. 321.

${ }^{32} \mathrm{El}$ pago al sastre en AHMVlr, Manual de Consejo $\mathrm{n}^{\mathrm{o}} 10$ bis (1418, diciembre 5). La otra referencia a Vila-real en M. GUAL, op. cit, p. 159. La referencia de archivo es AHMVlr, clavería 259 , fol. 13 v. Para las otras, véase apéndice prosopográfico.

${ }^{33}$ Pascual Miró, barbero de Valencia, sobrecolector general del reino, reconoce que Joan Colomer de Onda, ausente, le ha pagado a través de Francesc Falcó mercader de Valencia, 27 libras 10 ss "de tercia mensis iunii proxime lapsi de arrendamento quarterii generalis de Onda". ARV, prot. 1997 (1477, octubre 15). Los capítulos de arrendamiento de "Ta bulla" en Carlos FRADEJAS y Piedad GARCÍA, El régimen municipal en Onda a mediados del siglo XV, "Centre d'Estudis Municipal d'Onda", 2, 1989, pp. 53-55. 
en Castelló, donde también los paños comercializados crudos, sin especificación, bureles o de color oscuro, eran la mayoría. Y es que, cuando se requería un paño de mayor calidad, posiblemente Valencia fuese el marco de referencia, como en 1484, cuando los mudéjares Amet Lopo de Betxí, y Asmén Robaitén, alamín de Onda, confesaron deber 59 libras al lombardo Agostino da Ponte, precio de "un drap de llana", paño visiblemente mucho más caro que los aquí referenciados ${ }^{34}$.

\section{CUADRO I}

\section{Muestreo de compra-venta de paños en Onda}

\begin{tabular}{|c|c|c|c|c|}
\hline fecha & comprador & vendedor & pieza & precio \\
\hline 1412-03-01 & García Cantavella de Onda & Jaume Leó de Onda & drap & $30 s$ \\
\hline 1412-03-05 & Pere Vilagrassa de Onda & Jaume Pexó de Onda & drap vert & 10 flor $1 / 2$ \\
\hline $1412-04-21$ & Ferrando Lop de Onda & Miquel Mir & drap de lana moreno & $32 \mathrm{~s} 6 \mathrm{~d}$ \\
\hline $1412-05-22$ & $\begin{array}{l}\text { Cacim Raubil de Alcudia de } \\
\text { Fanzara }\end{array}$ & Joan Gallen de Onda & drap & $6 \mathrm{~s}$ \\
\hline $1412-06-10$ & $\begin{array}{l}\text { Gabriel Català, sastre de } \\
\text { Onda }\end{array}$ & Jaume Pexó de Onda & drap & $20 \mathrm{~s}$ \\
\hline $1412-07-27$ & PereRos, sastre de Onda & $\begin{array}{l}\text { Guillem Feliu de On- } \\
\text { da }\end{array}$ & drap & $37 \mathrm{~s} 2 \mathrm{~d}$ \\
\hline 1412-09-09 & $\begin{array}{l}\text { Joan Ros albardero converso } \\
\text { de Onda }\end{array}$ & Joan Romeu de Onda & drap blau & $43 \mathrm{~s}$ \\
\hline $1412-12-06$ & $\begin{array}{l}\text { Joan García canterero de } \\
\text { Onda }\end{array}$ & $\begin{array}{l}\text { Joan Romeu-Francesc } \\
\text { Almunia }\end{array}$ & drap vermell & $55 \mathrm{~s} 4 \mathrm{~d}$ \\
\hline $1417-08-19$ & Guillem Falcó de Onda & Joan Pinós de Betxí & drap & $100 \mathrm{~s}$ \\
\hline $1423-08-16$ & $\begin{array}{l}\text { Manuel Català, sastre de } \\
\text { Onda }\end{array}$ & $\begin{array}{l}\text { Guillem Aguilella de } \\
\text { Onda }\end{array}$ & drap burell & $11 \mathrm{~s}$ \\
\hline $1423-12-03$ & $\begin{array}{l}\text { Antoni de Sivilia, zapatero } \\
\text { de Onda }\end{array}$ & $\begin{array}{l}\text { Francesc Granell de } \\
\text { Onda }\end{array}$ & drap burell & $11 \mathrm{~s}$ \\
\hline $1437-02-14$ & Vicent Bonfill de Borriana & $\begin{array}{l}\text { Abrafim Capalmale, } \\
\text { judío de Onda }\end{array}$ & $\begin{array}{l}1 / 2 \text { peça de drap bu- } \\
\text { rell }\end{array}$ & $57 \mathrm{~s}$ \\
\hline $1437-05-16$ & Jaume Luca, de Onda & $\begin{array}{l}\text { Abrafim Capalmale, } \\
\text { judío de Onda }\end{array}$ & 5 alnes $1 / 2$ drap vert & $66 \mathrm{~s}$ \\
\hline
\end{tabular}

${ }^{34}$ En Cocentaina, entre 1469-1487, un $34 \%$ de los paños comercializados son crudos; un 47 $\%$ tintados en negro; en azul, morado o verde un $13 \%$; en rojo sólo un $6 \%$. Los colores denotan la cantidad de pastel utilizada, y el gusto de la moda campesina por los colores negros, azules y verdes. Mientras en Castelló se localizaba una producción de calidad media acorde con la coyuntura general valenciana, pues se realizaban paños a imitación de los franceses y flamencos, como los cordellates y los "vervins". Similar situación se observaba también en Segorbe. Véase J.A. LliBRER, op. cit, p. 43 y 87. P. IRADIEL et alii, op. cit, pp. 97-98. J. APARICI, El Alto Palancia, op. cit, pp. 60-64. El dato sobre el paño comprado al mercader italiano en D. IGUAL, Economia i comerç local, op. cit, p. 122. 


\begin{tabular}{|l|l|l|l|l|}
\hline 1500-04-01 & $\begin{array}{l}\text { Joan Ramo y Simó Perez de } \\
\text { Pavias }\end{array}$ & Franci Sempol & 7 alnes drap negre & $105 \mathrm{~s}$ \\
\hline $1501-01-13$ & Pere Prats de Nules & $\begin{array}{l}\text { Jaume Romeu, merca- } \\
\text { der de Onda }\end{array}$ & 3 alnes drap mescla & $30 \mathrm{~s}$ \\
\hline
\end{tabular}

Fuente: elaboración propia ${ }^{35}$.

Para concluir simplemente hacer una pequeña referencia a la presencia de las minorías religiosas en la industria textil ondense. Por un lado, y por lo que respecta al grupo judío, en 1450, ante la pretensión de que mudaran su domicilio al interior de la morería, se esgrimió que esto era perjudicial para los oficios que realizaban, especialmente orfebrería y sastrería. Sin embargo, el número de estos judíos no debía ser muy elevado, y algunos datos vislumbran la posibilidad de que no sean verdaderamente vecinos de la villa, sino que estén allí habitando temporalmente, siendo originarios de la cercana Burriana. A pesar de ello, los pocos datos reunidos confirman el hecho de que estaban integrados en las redes de intercambio a nivel local-comarcal. El judío Abrafim Capalmale, de quien se indica que es "jueu vehí de Burriana habitant en la vila d'Onda", en 1437 vendía paños pero también ropas, como a Domingo Garcia que confesó deberle 7 ss 11 dd razón de un "gipó" que le compró $^{36}$.

Mientras, el grupo mudéjar no aparece integrado en la comercialización de paños como los judíos, pero sí se observa su reiterada presencia en algunas fases de producción, especialmente como propietarios de la cabaña ganadera, o bien comercializando parte de las lanas que en sus manos se encontrarían, con una única mención a un oficio específico (Alí Faraig tintorero) y con ese batán y tinte en Ribesalbes que presuponía una producción propia por parte de los mudéjares habitantes en dicha alquería. Será sin embargo en la producción textil de lino donde esta minoría pueda quedar mejor integrada. La ya mencionada carta de población de 1405 muestra cómo los mudéjares de las alquerías de Onda eran "tenguts per casa filar una liura de li cascun any". Este lino también estaba fiscalizado en la primicia y diezmos eclesiásticos y era objeto de comercialización. Hamet Alcannar conocido con el alias de Almadioch, mudéjar de Onda, y Abdulamen Abixençi, de la alquería de Veo, se obligaron a pagar a Jaume Vives, vicario de Onda, 347 s por razón "e preu del lli que han comprat de la premecia e dels delmes de la part pertanyent al bisbe en la dita vila, a rahó de VI sólidos VII denarios lo feix". En 1478, Jucef y Mafomat Abocit de Ribesalbes,

\footnotetext{
${ }^{35} \mathrm{ARV}$, bailia general $\mathrm{n}^{0} 1304$ (1412), $\mathrm{n}^{0} 1305$ (1417), $\mathrm{n}^{0} 1306$ (1423), $\mathrm{n}^{0} 1307$ (1437), $\mathrm{n}^{\mathrm{o}}$ $1326(1500-01)$.

${ }^{36} \mathrm{ARV}$, bailia general $\mathrm{n}^{0} 1307$ (1437, enero 15). A Capalmale debemos unir la presencia de Mossé Ardit y Viđal Compte, de quienes también se indica que son de Burriana pero presentes en Onda. Ambos actúan en esta población el mismo día, 11 de abril de 1437, obligándose con el primero el ondense Miguel Guimerá en 7 ss 6 dd razón de una "jaqueta" que le compró mientras con el segundo se obligó Guillem Beltrán el menor, de Onda, pero por 13 flor. precio de una mula, siendo testigo del acto Abrafim Capalmale.
} 
confesaron deber al ondense Pere Martí 160 ss precio de 16 haces de lino. Más aún, en 1447, el consejo municipal de Castelló presentó una provisión para que los mudéjares del río Millars no lanzasen al agua corriente aquella agua que previamente les había servido para trabajar el lino, pues infectaban el caudal. Esos mudéjares son los que habitaban en la cuenca vertiente, río arriba, es decir, hacia Onda ${ }^{37}$.

\section{ESTUDIO PROSOPOGRÁFICO}

ANDRÉs, Ángel (1473) pelaire. Condenado por el justicia a pagar al tejedorJaume Andrés 8 ss 3 dd "de texidures e preu de vi". ARV, bailia general no 1314 (1473, julio 26).

ANDRÉS, Jaume (1473) tejedor. Véase ANDRÉS, Ángel.

ANDRÉs, Pere (1473) tejedor. El ondense Salvador Valero se obliga en pagarle 90 ss precio de cierto lino que le compró. ARV, bailia general no 1314 (1473, febrero 8).

AvinENT, Domingo (1458) tejedor. Avecinamiento oficial en Castelló, siendo fiador su propio hermano, el tejedor Pere Avinent. AHMCs, avecindamientos (1458, octubre 10).

BENEDITO, Miguel (1472-1473) "pilater". Joan Matamoros se obliga en pagarle 60 ss "per pilatadures que fet havia en lo seu molí". Un año después es condenado por el justicia en pagar a Çat Hamit, moro de Vila-Vella, 15 ss 4 dd como estima de las 9 alnas y media de "albadens" que le había encomendado para "adobar de molí, e aquelles serien perdudes". ARV, bailia general n 1313 (1472, enero ?), $\mathrm{n}^{\mathrm{o}} 1314$ (1473, abril 28).

BoNFILL, Miguel (1500) pelaire. "Comorant" en Onda, paz y tregua con el maestro de esgrima Lorenç Meseguer, natural de Mallorca pero habitante en Onda. ARV, bailia general $\mathrm{n}^{\circ} 1326$ (1500, marzo 13).

CAPOLAT, Francesc (1500) pelaire. Paz y tregua con el tonsurado Miguel Martí. ARV, bailia general $\mathrm{n}^{\circ} 1326$ (1500, enero 31).

CASA, Pere de (1478) pelaire. Compró al mercader italiano de Valencia Agostino da Ponte el 17 de octubre de 1478, 2 cargas 2 arrobas de pastel, precio de 17 libras, 6 ss 8 dd (D. IGUAL, op. cit, p.123).

CASSET, Pere (1472-1473) tintorero. En 1472, el tintorero de Villahermosa Bertomeu Mollo se obligó con Casset en 80 ss "per pacte de la companyia que entre aquells ere stada en possar una tina", cancelándose el 15 de octubre de 1473. Un año más tarde, es condenado por el justicia a pagar a Pere Romeu 20 ss debidos de 5 arrobas "de cendra les quals li havia trameses". Poco más tarde confesó tener un paño de Domingo Sancho notario de Onda, "per convertir aquell o lo procehit de aquell en pastell, e del procehit havia a respondre, e lo procehit fou C sous". Se compensan ciertos tintes que ya había hecho, y finalmente el justicia lo condena a pagar sólo $51 \mathrm{ss}$ al notario, pues parece ser el tintorero había perdido el paño. ARV, bailia general $n^{\circ} 1313$ (1472, agosto 27), $n^{\circ} 1314$ (1473, abril 23; julio 26).

${ }^{37}$ J. APARICI, Conexiones comerciales, op. cit, pp. 113-116. C. DÍAZ, Intercambios económicos, op. cit, p. 165 . Sobre las actividades artesanales en el ámbito textil desarrolladas por mudéjares valencianos, véase D. IGUAL, J.A. LLIBRER, G. NAVARRO, op. cit, pp. 319-325. 
CAPOLAT, Francesc (1472-1473) tejedor. Se obliga con Francesc Scuriola, tejedor de Onda, en 60 ss precio de un telar que le compró, cancelándose el 11 de enero de 1473 . Inventario de bienes de casa instando Jaume Agostí: "primo en la entrada un teler ab un pinte, ítem hun torn de filar ab sos arreus. En lo menjador una pastera e un ordidor. En la cambra un lit de V posts, petges, màrfega, travesser, una flaçada nova blanqua ab listes blanques e vermelles, un coffre nou pintat e vuyt”. ARV, bailia general $n^{\circ} 1313$; (1472, noviembre 13), $\mathrm{n}^{0} 1314$ (1473, abril 7).

DESCO, Miguel (1458) tejedor. Avecindamiento oficial en Castelló. AHMCs, avecinamientos (1458, mayo 17).

DíEZ, Rodrigo (1412) cardador. Condenado por el justicia a pagar al pelaire Francesc Granell 16 ss para cumplir una garantía que por él había dado. ARV, bailia general $n^{\circ} 1304$ (1412, febrero 23).

EXEMENO, Garcia (1447) pelaire. Avecindamiento oficial en Valencia en la parroquia de S. Joan del Mercat, por tiempo de 10 años $^{38}$.

FARAIG, Abrafim (1417) "moro tintorer d'Onda e vehí de Thoga”. Se obligó en pagar al ondense Joan Huguet 4 ss precio de una "cervellera". ARV, bailia general $\mathrm{n}^{\circ}$ 1305 (1417, enero 28).

GARCIA, Joan (1417-1423) pelaire. Pere Utrielles de Onda se obligó en pagarle 2 florines por el arrendamiento de una viña de García. Años más tarde se obligó en pagar al ondense Jaume Pexó 147 ss 5 dd precio de cierta lana, cancelándose el contrato el 14 de junio de 1423. ARV, bailia general $n^{\circ} 1305$ (1417, agosto 25), $\mathrm{n}^{\mathrm{0}} 1306$ (1423, abril 28).

GRANELL, Francesc (1412) pelaire. Véase DíAZ, Rodrigo.

LANÇOLA, Joan (1500) tejedor. Paz y tregua con el carpintero natural de Barcelona pero habitante en Onda Antoni Cardona. ARV, bailia general $n^{0} 1326$ (1500, marzo 21).

LLOBREGAT, Francesc (1448-1513) pelaire-tintorero. Confiesa deber cierta cantidad indeterminada al moro de Betxí Çuleymen Alcatraç, precio de lana (ARV, bailia general, $\mathrm{n}^{\mathrm{o}}$ 1308; 1448, abirl 18). Compró el 10 de julio de 1488 al mercader italiano de Valencia Corrado da Ponte 1 carga 2 arrobas de pastel precio de 8 libras, 12 ss 6 dd, y el 5 de diciembre de 1496 al también italiano Enrico Possobonello cierta cantidad de pastel no especificada por valor de 34 libras, 9 ss 4 dd. Testigo en un acto judicial (ARV, bailia general $n^{0} 1326 ; 1501$, febrero 2). Mención a su actuación como síndico de Onda el 26 de octubre de $1513^{39}$.

MARCO, Guillem (1456) pelaire. Avecindamiento oficial en Castelló. AHMCs, avecinamientos (1456, septiembre 28 ).

MARÍ Joan (1495) pelaire. Instancia judicial de Francesc Martí, procurador del mercader castellonense Joan Eximeno, para que pague las 12 libras restantes de las 16 libras precio de cierta lana, según contrato ante A. Feliu el 5 de octubre de 1494. AHMCs, justicia ${ }^{\circ} 20$, letras (1495, julio 13).

MATAMOROS, Joan (1465-1472) pelaire. Revoca como procurador suyo al pelaire castellonense Blai Visiedo, nombrando a Nadal Martí alias Canyelles. Años más tarde se obliga en pagar 60 ss a Miquel Benedito "per pilatadures que fet havia en lo seu molí". AHMCs, justicia $n^{0} 16$, actos comunes (1465, abril 30). ARV, bailia general $\mathrm{n}^{\circ} 1313$ (1472, enero ?)

${ }^{38}$ L. PILES, La repoblación de Valencia, op. cit. Doc. ${ }^{0}$ 1262, fechado el 1447, mayo 9.

${ }^{39} \mathrm{D}$. IGUAL, op cit, p. 123. J. APARICI, A.V. FRANCH,, Regesta de documents en pergamí de l'Arxiu Históric Municipal d'Onda, "Estudis Castellonencs", 5, (1992-93), p. 622. 
MORANT, Benet (1473) tintorer. "Comorant" en Onda se obliga en pagar a Joan Arnau, de Onda, 6 ss 2 dd precio de un puñal. ARV, bailia general $n^{0} 1314$ (1473, enero 7).

PENAFEL, Jaume (1500) pelaire. Testigo de un acto judicial. ARV, bailia general $\mathrm{n}^{\mathrm{o}}$ 1326 (1500, enero 23).

PEREÇ, Miquel (1504-1511) tintorero. El 8 de noviembre de 1504, Luís Ángel d'Exarch, habitante de Valencia confesó recibir de Péreç en nombre Onda los 147 ss 6 dd que la villa le hace cada 16 de octubre. Años después, el 31 de marzo de 1511 , actúa como a síndico de la villa en un "quitament" censal ${ }^{40}$.

Querol, Domingo (1420) tintorero. Se indica que el 8 de junio de 1419 se afirmó con el mercader de Castelló Lorenç Miquel por tiempo de un año "a complir e treballar e usar de son officii de tintorer e de perairia, axí en lo tint del dit Lorenç que té en Castelló", diciendo Querol que allí trabajaría si había labor, y si no que "treballarie com a baxador de draps, tirar e apuntar aquells en casa del dit Lorenç". Además prometió cuidar el pastel, la roja y otros tintes necesarios. Se acordó que la soldada sería de 60 florines a pagar al final del año. Pero ahora Lorenç reclama porque Querol no ha trabajado durante 3 meses, puesto que cuando el tinte tuvo un paro estacional Querol no quiso ir a su casa "per a baxar draps, dient que se n'anava a Onda e en altres parts". Además lo acusa de robarle dinero, calzados y tintes, por valor de 15 florines. AHMCs, justicia $\mathrm{n}^{\mathrm{0}} 1$, letras, folios sueltos (1420, noviembre 17).

REVERT, Bertomeu (1501) "abaxador". Paz y tregua establecida entre Revert y Mafomat Toledano moro castellano que habita en la morería de Onda. ARV, bailia general $n^{0} 1326$ (1501, enero 4).

RocA, Francesc (1473) tejedor. Confesó haber prometido pagar a Alvarico, mozo suyo, una soldada de 11 ss mensuales. Al no haberlo hecho, es condenado por el justicia a pagar al mozo 16 ss 6 dd por un mes y medio que trabajó. ARV, bailia general $\mathrm{n}^{\mathrm{o}} 1314$ (1473, junio 18).

SABATER, Jaume (1500) pelaire. Disputa y riña entre Antoni de Patos el menor y Romeu, hijo de Jaume. ARV, bailia general no 1326 (1500, enero 23).

SABATER, Pere (1495) tintorero. Testigo en un acto judicial. AHMCs, justicia n ${ }^{0} 20$, actos comunes (1495, mayo 18).

SALA, Guillem (1472-1473) tintorero. En 1472 se obligó en pagar a Antoni Palomar el menor, también de Onda, 64 ss precio de un quintal de lana, a razón de 16 ss la arroba. Más tarde, Joan Roiz de Corella, conde de Cocentaina y consejero del rey envía una carta al justicia de Onda, indicándole que según una carta dada en Valencia el 25 de agosto de ese año, se mandó a Sala que en 10 días pagase al mercader Gabriel de la Esglesia $8 \mathrm{lb}, 12$ ss 4 dd debidos de cierto producto no especificado, y al no haberlo hecho, lo requiere para subastar sus bienes. ARV, bailia general, $\mathrm{n}^{\mathrm{o}} 1313$ (1472, diciembre 18), $\mathrm{n}^{\mathrm{o}} 1314$ (1473, octubre 7). En referencia a este último documento, el acto de compra está fechado el 15 de febrero de 1473 y aparece documentado por D. Igual, indicándose que el vendedor es Gabrielle della Chiesa, un mercader italiano afincado en Valencia, y que la deuda corresponde al precio de una carga y una arroba de pastel ${ }^{41}$.

SALA, Miguel (1500) pelaire. Testigo en una compra-venta de cueros. ARV, bailia general $n^{0} 1326$ (1500, enero 31).

\footnotetext{
${ }^{40}$ J. APARICI, A.V. FranCH, op. cit, p. 621.

${ }^{41}$ D. IGUAL, op. cit, p. 123.
} 
SANÇ, Pere (1412) pelaire. Condenado por el justicia en pagar, como a fiador de Joan de Patos, 6 ss 6 dd que éste debía a Alí Abrafim, moro de la Alcudia de Veyo. Se canceló el 30 de junio de ese año. Poco más tarde se obligó en pagar a Alí Alfarapell de Fanzara 38 ss razón de cereal que le compró, cancelándose el 15 de julio de ese año. ARV, bailia general no 1304 (1412, mayo 27; junio 16).

SCURIOLA, Francesc (1472) tejedor. Vendió a Francesc Conca tejedor de Onda, un telar precio de $60 \mathrm{ss}$, cancelándose el 11 de enero de 1473. ARV, bailia general $n^{0} 1313$ (1472, noviembre 13).

SCURIOLA, Nicolau (1525) maestre tintorero. Referencia a que originario de Onda está habitando en Castelló. AHMCs, justicia $\mathrm{n}^{0} 39$, actos comunes (1525, junio 28).

SCURIOLA, Miguel (1485) pelaire. Actúa como a procurador de Guillem Saborit, vecino de Vistabella. AHMCs, Procesos corte justicia $\mathrm{n}^{0} 1$ (1485, enero 12).

VENRELL, Joan (1472) "texedor natural del loch de Campos, de l'Illa de Mallorqua". Testigo requerido para aclarar la agresión a una prostituta de Onda, si bien él indica no conocer a los agresores pues "no haia sino tres o quatre setmanes que és en aquesta vila". ARV, bailia general $\mathrm{n}^{\circ} 1313$ (1472, mayo 2).

VILAGRASSA, Domingo (1412-1437) tejedor. Condenado por el justicia en pagar a los capellanes de Onda 5 ss 6 dd debidos de cierto censo. Años después se obligó en pagar a Bonanat Pujades, capellán procurador de aquellos, 8 ss de censo debido desde la fiesta de S. Miguel ya pasada. ARV, bailia general $\mathrm{n}^{0} 1304$ (1412, septiembre 6), $\mathrm{n}^{\mathrm{O}} 1307$ (1437, julio 19).

Fecha de recepción del artículo: junio 2009.

Fecha de aceptación y versión final: enero 2010. 
